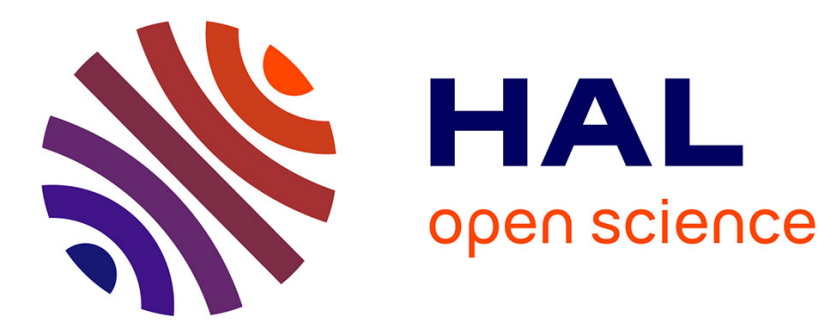

\title{
Cellular prion protein dysfunction in a prototypical inherited metabolic myopathy
}

Fatima-Zohra Boufroura, Céline Tomkiewicz-Raulet, Virginie Poindessous, Johan Castille, Jean-Luc Vilotte, Jean Bastin, Sophie Mouillet-Richard, Fatima Djouadi

\section{To cite this version:}

Fatima-Zohra Boufroura, Céline Tomkiewicz-Raulet, Virginie Poindessous, Johan Castille, Jean-Luc Vilotte, et al.. Cellular prion protein dysfunction in a prototypical inherited metabolic myopathy. Cellular and Molecular Life Sciences, 2020, Online ahead of print. 10.1007/s00018-020-03624-6 . inserm-02948111

\section{HAL Id: inserm-02948111 https://www.hal.inserm.fr/inserm-02948111}

Submitted on 24 Sep 2020

HAL is a multi-disciplinary open access archive for the deposit and dissemination of scientific research documents, whether they are published or not. The documents may come from teaching and research institutions in France or abroad, or from public or private research centers.
L'archive ouverte pluridisciplinaire HAL, est destinée au dépôt et à la diffusion de documents scientifiques de niveau recherche, publiés ou non, émanant des établissements d'enseignement et de recherche français ou étrangers, des laboratoires publics ou privés. 


\section{Cellular prion protein dysfunction in a prototypical inherited metabolic myopathy}

Fatima-Zohra Boufroura ${ }^{1}$, Céline Tomkiewicz-Raulet ${ }^{2}$, Virginie Poindessous ${ }^{1}$, Johan Castille $^{3}$, JeanLuc Vilotte $^{3}$, Jean Bastin ${ }^{1}$, Sophie Mouillet-Richard ${ }^{1{ }^{*}}$, Fatima Djouadi ${ }^{1{ }^{*}}$

* Sophie Mouillet-Richard and Fatima Djouadi are co-senior authors

1. Centre de Recherche des Cordeliers, INSERM, Sorbonne Université, Université de Paris, F75006 Paris, France

2. Centre Universitaire des Saints Pères, INSERM U1124, Sorbonne Université, Université de Paris, F-75006 Paris, France

3. Université Paris-Saclay, INRAE, AgroParisTech, UMR1313, Génétique animale et biologie intégrative, F78350 Jouy-en-Josas, France

\section{Correspondance}

Dr Sophie Mouillet-Richard

or

Dr Fatima Djouadi

Centre de Recherche des Cordeliers, INSERM U1138

15, rue de L'Ecole de Médecine

75006 Paris, France

E-mail: sophie.mouillet-richard@parisdescartes.fr or fatima.djouadi@inserm.fr 


\section{Summary}

Inherited fatty acid oxidation diseases in their mild forms often present as metabolic myopathies. Carnitine Palmitoyl Transferase 2 (CPT2) deficiency, one such prototypical disorder is associated with compromised myotube differentiation. Here, we show that CPT2-deficient myotubes exhibit defects in focal adhesions and redox balance, exemplified by increased SOD2 expression. We document unprecedented alterations in the cellular prion protein $\operatorname{PrP}^{\mathrm{C}}$, which directly arise from the failure in CPT2 enzymatic activity. We also demonstrate that the loss of $\operatorname{PrP}^{C}$ function in normal myotubes recapitulates the defects in focal adhesion, redox balance and differentiation hallmarks monitored in CPT2-deficient cells. These results are further corroborated by studies performed in muscles from $\operatorname{Prn}^{-/}$mice. Altogether, our results unveil a molecular scenario whereby $\operatorname{PrP}^{C}$ dysfunction governed by faulty CPT2 activity may drive aberrant focal adhesion turnover and hinder proper myotube differentiation. Our study adds a novel facet to the involvement of $\operatorname{PrP}^{C}$ in diverse physiopathological situations.

Key words: inherited metabolic myopathy, cellular prion protein, muscle differentiation, inherited fatty acid oxidation disorders, focal adhesions, redox balance 


\section{Introduction}

Skeletal muscle dysfunction represents a frequent hallmark of inborn metabolic disorders [1]. One prototypical metabolic myopathy is the deficiency in Carnitine Palmitoyl Transferase 2 (CPT2), one of the most common inherited fatty acid oxidation (FAO) disorders. Until recently, the pathophysiological mechanisms underlying skeletal muscle defects in CPT2-deficient patients had remained enigmatic. Taking advantage of a unique collection of myoblasts from CPT2-deficient patients harboring "mild" mutations, associated with residual enzyme activity and responsible for the most frequent disease phenotype characterized by myalgia, stiffness, cramps, rhabdomyolysis and exercise intolerance [2], we highlighted for the first time the existence of an impaired differentiation process in CPT2-deficient myotubes [3]. Notably, myotubes from CPT2-deficient patients display reduced fusion index and decreased levels of myotubes differentiation markers such as the myosin heavy chain (MHC) [3]. However, the cascade of molecular events driving the alterations in myotube differentiation in the context of CPT2 deficiency remains to be fully elucidated. In the present work, we sought to assess the impact of CPT2 deficiency on focal adhesions (FA), whose remodeling is mandatory for myoblast fusion (reviewed in [4]). In particular, we focused on focal adhesion kinase (FAK), a pivotal nonreceptor protein tyrosine kinase that has been well studied for its pleiotropic role in muscle development and homeostasis [5].

We further evaluated a contribution of the cellular prion protein $\operatorname{PrP}^{\mathrm{C}}$, which, beyond being infamous for its involvement under its scrapie isoform $\mathrm{PrP}^{\mathrm{Sc}}$ in a group of neurodegenerative diseases [6], is known to play a role in cellular redox balance [7] and was also reported to take part to focal adhesion turnover [8,9]. Interestingly, several studies have shown that different models of mice overexpressing $\operatorname{PrP}^{C}$ [10-12] develop a progressive myopathy sometimes associated with mitochondrial hyperplasia [12]. On another hand, although PrP null mice do not show any obvious muscle abnormality, the absence of $\operatorname{PrP}^{C}$ delays the regeneration of both glycolytic and oxidative fibers after acute muscle damage [13] and affects the profiles of muscle fibers $[14,15]$ as well as the expression of mitochondrial markers in skeletal muscles of aged individuals [16]. Finally, mice lacking PrP show reduced tolerance for physical exercise $[16,17]$. Altogether, studies showing that the over-expression of $\operatorname{PrP}^{C}$, or its absence, all have severe consequences on muscle, additionally warrant examining $\mathrm{PrP}^{\mathrm{C}}$ in $\mathrm{CPT} 2-$ deficient myotubes. 
Here we show that CPT2 deficiency triggers ROS imbalance and $\operatorname{PrP}^{\mathrm{C}}$ loss-of-function, which contribute to impair myotube formation by altering focal adhesions dynamics. 


\section{Methods}

\section{Cell culture and treatments}

Controls $(n=3)$ and CPT2-deficient $(n=4)$ human myoblasts used in this study were obtained from individuals that gave informed consent for research use and have been previously described in details $[18,19,3]$. Myoblasts were cultured in Ham's F10 with Glutamax (GIBCO) containing 20\% FBS, 0.5\% Ultroser G, $0.2 \%$ Primocin and $1 \mathrm{mM}$ Carnitine. At $80-90 \%$ confluence myoblasts were induced to differentiate for 6 days in DMEM with Glutamax (GIBCO) supplemented with $2 \%$ horse serum, $0.2 \%$ Primocin and $1 \mathrm{mM}$ Carnitine. Cells were cultured at $37^{\circ} \mathrm{C}$ at $5 \% \mathrm{CO}_{2}$. In some experiments, control myoblasts were switched to differentiation medium containing $2 \mathrm{mM}$ L-Amino-Carnitine (gift from Sigma-Tau, Italy) for 6 days. For transient siRNA-mediated silencing, myoblasts were transfected with siRNA sequences (30 nM) using the Lipofectamine RNAiMAX reagent according to the manufacturer's instructions (Invitrogen) and directly induced to differentiate. Specific siRNA sequences used were: 5'CAGUACAGCAACCAGAACATT-3' (sense siPRNP) 5'-AACGAUGACACGAACACACTT-3' (sense non-target, NT),

\section{Animal studies}

All animal experiments were carried out in strict accordance with the recommendations in the guidelines of the Code for Methods and Welfare Considerations in Behavioral Research with Animals (Directive 2016/63/UE). All efforts were made to minimize suffering. Experiments were approved by the INRAE local animal experiment ethics committee of Jouy-en-Josas (Comethea, Permit Number 02532.01). FVB/NJ Prnp ${ }^{-1-}$ mice were established through the CRISPR/Cas9 technology and will be described in detail in an upcoming publication. Hind limb muscles (Gastrocnemius) from four-monthold male FVB/NJ Prnp ${ }^{-/}$mice and their wild-type isogenic FVB/NJ controls were dissected and immediately frozen in liquid nitrogen. Samples were stored at $-80^{\circ} \mathrm{C}$ until analysis.

\section{Western blotting}

Myotubes were lysed in a buffer containing $50 \mathrm{mM}$ Tris- $\mathrm{HCl} \mathrm{pH} 8,150 \mathrm{mM} \mathrm{NaCl}, 0.5 \%$ Nonidet P40, $0.25 \%$ sodium deoxycholate, $0.1 \%$ sodium dodecyl sulfate (SDS), $1 \mathrm{mM}$ de phenylmethylsulfonyl fluoride, 1x protease inhibitor cocktail, (Complete mini, Roche), 1x Phosphatase inhibitor cocktail 
(PhosSTOP, Roche), 10mM Nicotinamide. Protein concentration was determined by the Lowry method. Cytoplasmic and nuclear extracts were obtained using a kit from Thermo Scientific according to the manufacturer's instructions and the same total protein amounts of membrane/cytosolic and nuclear fraction were loaded in the gel. For $\mathrm{PrP}^{\mathrm{C}}$ protein, $\mathrm{PNGaseF}$ treatment was performed

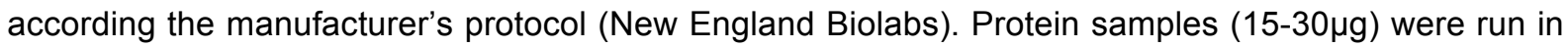
BoltTM $10 \%$ Bis-Tris Plus gels (Invitrogen) or $10 \%$ or $12 \%$ SDS-PAGE and transferred to PVDF membranes (Biorad). Membranes were blocked with $5 \%$ milk or $5 \%$ BSA in 1x TBS-T for $1 \mathrm{~h}$ before incubation with primary antibodies overnight at $4^{\circ} \mathrm{C}$. Immunoreactive bands were analyzed with a computerized video densitometer or with a LAS-4000 luminescent image analyzer. The results were expressed as arbitrary units normalized to the amount of an appropriate reference protein: Tubulin for total cell extracts, Hsp90 for the membrane/ cytosolic extracts and Lamin A/C for the nuclear extracts. Most of the time, blots were stripped using Antibody Stripping Buffer (Gene Bio-Application) according to the manufacturer's instructions and probed again. The following antibodies were used: rabbit polyclonal anti-CPT2 (Millipore), mouse monoclonal anti-tubulin (Sigma-Aldrich), mouse monoclonal anti-myosin, Skeletal, Slow (Sigma-Aldrich), rabbit polyclonal anti-FAK (Cell Signaling), rabbit monoclonal anti-paxillin (Abcam), mouse monoclonal anti-SOD2 (Abcam), mouse monoclonal anti$\operatorname{PrP}^{C}$ (Sha31, SPI-Bio), the Sha31 monoclonal antibody targets the epitope corresponding to aminoacids 145-152 (human numbering), rabbit polyclonal anti-MYF5 (Abcam), rabbit polyclonal anti-Hsp90 (Abcam), mouse monoclonal anti-Lamin A/C (Cell Signaling).

\section{RNA analysis}

RNA was isolated by using the RNeasy extraction kit (Qiagen, Limburg, Netherlands), as recommended by the manufacturer's instructions. cDNA was generated from $1 \mu \mathrm{g}$ of total RNA using the High-capacity cDNA Reverse Transcription (Applied Biosystems) and quantified in triplicates on the 7900HT Fast Real-Time PCR system (Applied Biosystems) using Absolute qPCR SYBR Green ROX Mix (Thermo Scientific). The primer sequences are shown below:

PRNP-F: CGAGCTTCTCCTCTCCTCAC; PRNP-R: GTTCCATCCTCCAGGCTTC; MYH7-F: GACATGCTGCTGATCACCAACA; MYH7-R: CGCCTGTCAGCTTATACATGGA; SOD2-F: GAGTTGCTGGAAGCCATCAAAC; $\quad$ SOD2-R: $\quad$ TGGAATAAGGCCTGTTGTTCCT; $\quad$ MYF5-F: TGCCAGTTCTCACCTTCTGAGT; MYF5-R: TCGCACGTGCTGGTCCTCAT; $\quad$ RPL13A-F: 
CCTGGAGGAGAAGAGGAAAGAGA; RPL13A-R: GAGGACCTCTGTGTATTTGTCAA. The results are expressed as the relative quantification of a target gene transcript normalized to RPL13A housekeeping gene, using the $\Delta \Delta \mathrm{Ct}$ method.

\section{Immunofluorescence}

Myotubes were fixed $20 \mathrm{~min}$ in $4 \%$ paraformaldehyde and permeabilized for $3 \mathrm{~min}$ by $0.2 \%$ Triton/PBS. Cells were washed and pre-incubated in PBS/1\% BSA/0.3M Glycine for $30 \mathrm{~min}$. The cells were then incubated $1 \mathrm{~h}$ at room temperature, with the primary antibody diluted in PBS containing $1 \%$ BSA. Antibodies used for immunofluorescence experiments are identical to those used for western blotting except for FAK (Abcam). Myotubes were washed three times in PBS/ $0.1 \%$ Tween and then incubated $1 \mathrm{~h}$ at room temperature, with secondary antibody anti-rabbit Alexa Fluor 546 and/or anti-mouse Alexa Fluor 488 (Life Technologies). F-actin fibers were stained with TRITC-Phalloidin (250 $\mu \mathrm{g} / \mathrm{ml})$ (SigmaAldrich) diluted in PBS containing 1\% BSA for $1 \mathrm{~h}$ at room temperature. Nuclei were stained with bluefluorescent TO-PRO-3 (Invitrogen). Coverslips were washed and mounted in Dako mounting medium (Dako corporation). Images were acquired on a Carl-Zeiss LSM 510 META confocal microscope and analyzed with Zeiss LSM Image Browser software.

\section{Statistical analysis}

The results are presented as the mean \pm SEM. All statistical analyses were performed using GraphPad Prism software (version 6.0). Data distribution was first checked for normality using the Shapiro-Wilk test, and parametric or non-parametric tests were then applied accordingly. Differences between groups were analyzed by Mann-Whitney test, or paired or unpaired two-tailed Student's $t$ test for the comparison of two groups, or by Two-way ANOVA and the Tuckey test for comparison of four groups. The statistical tests used are indicated in the figures' legends. $P<0.05$ was considered significant. 


\section{Results and Discussion}

\section{CPT2-deficient myotubes exhibit a remodeling of focal adhesions.}

We hypothesized that CPT2 deficiency in myotubes, which is associated with reduced levels of CPT2 and MHC-I proteins (Fig. S1) as previously demonstrated [3], is accompanied by alterations in focal adhesions (FAs). To address this question, we evaluated the distribution of the FA scaffold protein Paxillin (PAX) in myotubes from CPT2-deficient patients and healthy subjects by immunofluorescence. While control cells exhibited a diffuse cytoplasmic staining of PAX associated with a high MHC-I fluorescence intensity, CPT2-deficient myotubes showed intense cytoplasmic PAX-positive dots and a reduced MHC-I staining (Fig. 1A), with no change in PAX protein levels (Fig. 1B), suggesting that the defect in CPT2 is associated with an intracellular redistribution of PAX and increased FA number. In further support of this hypothesis, we found a striking difference in the amount and distribution of the Focal Adhesion Kinase (FAK), a key FA adaptor protein, between patients- and control-derived myotubes. Indeed, control cells showed a strong cytoplasmic signal comparable to that obtained with PAX, while in contrast, we monitored a very weak signal only in CPT2-deficient myotubes (Fig. 1C). The reduction in FAK protein levels in CPT2-deficient cells could be firmly substantiated in western blot experiments (Fig. 1D) and likely accounts for the stabilization of FAs as seen in Figure 1A [20]. This decrease most likely participates to the mechanisms leading to the impaired differentiation process revealed in our previous study [3]. Indeed, FAK inhibition in mouse primary myoblasts was shown to result in a marked impairment of myoblast fusion, a critical step of myogenesis [21].

FAK activation requires ROS-dependent inactivation of phosphatases [22]. Importantly, it has been shown that de-phosphorylation of FAK by phosphatases may be associated with FAK degradation [20]. Thus, the decreased level of FAK observed in CPT2-deficient myotubes might be due to an increased FAK degradation, itself due to more active phosphatases resulting from a reduction in ROS levels. This hypothesis fully fits in with our previous observation that ROS levels are significantly decreased in CPT2-deficient myotubes compared to controls [3]. However, finding that ROS levels were lower in CPT2 cells was first very surprising to us since it is widely admitted that FAO defects, like many others inherited mitochondrial disorders, are rather associated with oxidative stress [23]. This is why we went on assessing the expression of the central antioxidant enzyme SOD2 in CPT2deficient myotubes. Of note, we found that CPT2-deficient myotubes expressed higher levels of both 
SOD2 mRNA and protein than healthy control cells (Fig. 1E). Thus, as a possible scenario, we propose that the inherited CPT2 deficiency is permanently generating ROS and that a compensatory mechanism to adapt to this high level is to increase the expression of SOD2, which ultimately results in a low level of ROS as measured in the CPT2-deficient cells [3]. Altogether, these results reveal an abnormal distribution of PAX associated with a lower level of FAK likely due to a complex loop in the regulation of ROS levels in CPT2-deficient myotubes. It can be surmised that these changes alter adequate dynamics at FAs in the protrusions of migrating myoblasts and thereby hamper proper migration and fusion.

\section{CPT2-deficient myotubes reveal an alteration in the cleavage of $\operatorname{PrP}^{\mathrm{C}}$}

Because the cellular prion protein $\operatorname{PrP}^{C}$ is increased during the differentiation of muscle cells [14] and its deficiency is associated both with impaired FA turnover [8,9] and muscle function [13], we anticipated that alterations in this protein might take part to the defects observed in CPT2-deficient patients. The deficiency in CPT2 had no impact on PRNP transcripts encoding $\operatorname{PrP}^{\mathrm{C}}$ in myotubes (Fig. 2A). Next, protein extracts were submitted to deglycosylation with PNGaseF, in order to better estimate the amount of $\operatorname{PrP}^{C}$ as well as its cleavage products. The two main processing events described for $\mathrm{PrP}^{\mathrm{C}}$ are the so-called alpha- and beta-cleavages, yielding N1/C1 and N2/C2 fragments, respectively (reviewed in [24]) (Fig.S2). Whereas the $\mathrm{N} 1 / \mathrm{C} 1$ cleavage of $\mathrm{PrP}^{\mathrm{C}}$ mainly depends on proteases, the N2/C2 cleavage is, for its part, primarily triggered by ROS [25,26]. As shown in Fig. 2B, patients exhibited reduced levels of the full-length $(\mathrm{FL}) \mathrm{PrP}^{\mathrm{C}}$ isoform together with increased levels of the $\mathrm{C} 2$ isoform, while the shorter $\mathrm{C} 1$ isoform slightly increased without reaching significance. We were initially puzzled by the fact that the $\mathrm{FL}-\mathrm{PrP}^{\mathrm{C}}$ was not the major $\operatorname{PrP}^{\mathrm{C}}$ fraction in control human myotubes, and that C1- and C2-isoforms exhibited higher levels compared to the FL. However, similar profiles of $\operatorname{PrP}^{C}$ isoforms have been recently reported in polarized retinal epithelial cells [27] and in mouse pancreas [28].

To further characterize the expression pattern of $\mathrm{PrP}^{\mathrm{C}}$ in CPT2-deficient myotubes, we examined its intracellular distribution in permeabilized cells through immunofluorescence experiments. $\operatorname{PrP}^{\mathrm{C}}$ mostly co-localized with PAX in control cells while, strikingly, we observed a strong nuclear $\operatorname{PrP}^{C}$ staining in CPT2-deficient myotubes, which was not present in healthy cells (Fig. 2C). This observation was fully corroborated with western blot analyses of nuclear vs. cytoplasmic/membrane extracts from CPT2- 
deficient and control myotubes (Fig. 2D). Indeed, while all isoforms were mostly non-nuclear in control cells, we detected significant levels of $\mathrm{C} 1$ and majorly $\mathrm{C} 2$ isoforms in the nuclear fraction of CPT2deficient myotubes. These experiments further confirmed the robust increase in $C 2-\operatorname{PrP}^{\mathrm{C}}$ in the myotubes of CPT2-deficient patients, as seen in whole cell extracts (Fig. 2B). Thus, these data exemplify strong changes in $\mathrm{PrP}^{\mathrm{C}}$ processing and localization in CPT2-deficient myotubes. The nuclear localization of a fraction of $\operatorname{PrP}^{\mathrm{C}}$ in CPT2-deficient cells is a puzzling observation and will deserve further investigation. Very little is known on nuclear $\operatorname{PrP}^{\mathrm{C}}$, although it has been described in a few studies. For instance, Bravard et al. reported on the nuclear targeting of $\operatorname{PrP}^{\mathrm{C}}$ in response to genotoxic stress, where it interacts with the DNA repair enzyme Apurinic/apyrimidinic endonuclease 1 and serves a protective function [29]. In line with this, $\operatorname{PrP}^{C}$ was shown to protect against DNA damage induced by oxidative stress [30]. Indeed, oxidative stress is a well-established inducer of DNA damage, see review [31]. Thus, we may surmise that the nuclear targeting of a fraction of $\operatorname{PrP}^{C}$ in CPT2-deficient cells may be a consequence of oxidative stress, similarly to $\operatorname{PrP}^{\mathrm{C}}$ beta-cleavage.

\section{$\operatorname{PrP}^{\mathrm{C}}$ alterations are driven by CPT2 enzymatic deficiency}

Next, we sought to assess whether the alterations in $\operatorname{PrP}^{C}$ described above directly arise from an impairment of CPT2 enzymatic activity rather than indirectly from a confounding effect of the CPT2 mutation. To this purpose, control myoblasts were induced to differentiate in the presence of $2 \mathrm{mM} \mathrm{L-}$ Amino-Carnitine (L-Amino-Car), a specific inhibitor of CPT2 [32], for 6 days. We previously demonstrated that this concentration of L-Amino-Car strongly inhibits fatty acid oxidation in human myoblasts [33]. As shown in Fig. 3A, L-Amino-Car-treated myotubes exhibited significantly reduced levels of MHC-I and FAK together with increased levels of SOD2, thus recapitulating the alterations found in genetically CPT2-deficient myotubes. Hence, L-Amino-Car appears to interfere with myotube differentiation, a conclusion that is further supported by the increase in MYF5, a marker of myoblasts lost once committed to differentiation [34], after L-amino-Car treatment (Fig. 3A). Of note, L-amino-Car promoted a decrease in FL-PrPC accompanied by increases in the $\mathrm{C} 1$ and $\mathrm{C} 2$ cleaved isoforms (Fig. 3B). We may thus conclude that exposure of healthy myotubes to L-amino-Car reproduces the molecular features observed under genetic CPT2 deficiency, including at the level of $\operatorname{PrP}^{\mathrm{C}}$. As a corollary, these results indicate that impaired CPT2 enzymatic function fosters $\operatorname{PrP}^{\mathrm{C}}$ alterations. 


\section{$\operatorname{PrP}^{\mathrm{C}}$ loss of function recapitulates specific features of CPT2-deficiency}

These observations raise the question as to how $\operatorname{PrP}^{C}$ alterations may contribute to altered myotube

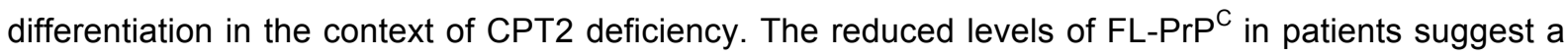
loss-of-function phenotype. To address this possibility, we probed the impact of siRNA-mediated PrP ${ }^{C}$ silencing in control myotubes. Remarkably, $\operatorname{PrP}^{C}$ depletion (Fig. 4A) triggered significant decreases in both MHC-I and FAK protein levels, while it promoted strong upregulations in the protein levels of SOD2 and MYF5 thereby mimicking the changes observed in CPT2-deficient myotubes (Fig. 4B). These defects appear to arise from changes in gene expression since $\operatorname{PrP}^{\mathrm{C}}$-silenced cells expressed lower levels of MYH7 mRNA encoding MHC-I and higher amounts of SOD2 and MYF5 transcripts (Fig. 4C). Finally, we found that the impact of $\mathrm{PrP}^{\mathrm{C}}$ knockdown compared that of CPT2 genetic deficiency when examining the cellular distribution of Paxillin and MHC-I in immunofluorescence staining (Fig. 4D). Importantly, $\operatorname{PrP}^{C}$ silencing in control myotubes reproduced the impaired commitment to terminal differentiation of CPT2-deficient myotubes previously described in [3], as indicated by the decreased myogenic fusion index (\%of nuclei present in MHC-stained myotubes) (Fig. 4E). Corroborating these results, we monitored reduced MHC-I and FAK proteins together with increased levels of SOD2 in muscles from Prnp ${ }^{-/-}$mice (Fig. 4F and 4G). Altogether, these data strongly support the view that the alterations of $\operatorname{PrP}^{C}$ promoted by the deficit in CPT2 activity induce a loss-of-function phenotype, itself contributing to defective myotube differentiation and FA turnover.

In summary, we have established that the impairment of differentiation is associated with defects in FAs turnover in CPT2 patients' cells and that both genuinely arise from the deficit in CPT2 enzymatic activity. A second important conclusion of this work is that changes in $\operatorname{PrP}^{C}$ appear to exert a central role in the СРT2-dependent phenotype. Altogether, our findings allow proposing a molecular scenario (Fig. $4 \mathrm{H}$ ) whereby reduced CPT2 activity in patients-derived cells would, in the first place, trigger a situation of oxidative stress, boosting the production of $\mathrm{C}^{-}-\mathrm{PrP}^{\mathrm{C}}$ via beta-cleavage [26]. $\mathrm{C}^{2}-\mathrm{PrP}^{\mathrm{C}}$ would, in turn, help cells cope with this oxidative stress situation as depicted for this isoform $[30,26]$ and, in the end, would generate a chronic state of defence against ROS, notably based on elevated SOD2 levels. Therefore, the beta-cleavage of $\operatorname{PrP}^{C}$ can be considered as a surrogate marker of excessive ROS production. Importantly, this scenario might also reconcile the literature data generally indicating variable ROS levels in various inherited muscle diseases [35,23], which could originate from 
different capacities of the muscle to cope for excessive ROS production as a compensatory mechanism $[36,37]$.

Furthermore, the loss-of-function phenotype ensuing from $\operatorname{PrP}^{C}$ beta-cleavage would hinder FA turnover and thus disrupt myoblasts fusion and thereby myotubes formation. Noteworthy, this situation is highly reminiscent of the neuronal differentiation defects observed upon $\operatorname{PrP}^{C}$ silencing. Indeed, knock-down of $\operatorname{PrP}^{C}$ in neuronal cells leads to reduced FA turnover, and increased stability of actin microfilament, which inhibits neuritogenesis [8]. Likewise, we observed altered/thicker F-actin fibers in CPT2-deficient myotubes (Fig. S3). Of particular interest, increased mitochondrial SOD2 activity was also reported in brain extracts from $\operatorname{PrP}^{C}$ knockout mice [38]. Furthermore, it was recently shown that exposure of neural stem cells (NSC) to synthetically produced N1 or N2 fragments resulted in reduced migration and neurite outgrowth [39]. These cellular changes were accompanied by a reduction in intracellular ROS production and an increased SOD2 level. The authors also reported enhanced mitochondrial fission in NSC treated with $\mathrm{N} 1 / \mathrm{N} 2$, which is reminiscent of the higher mitochondrial fission that we previously reported in CPT2-deficient myotubes [3].

Altogether, the data presented here identify for the first time $\operatorname{PrP}^{C}$ as a novel and crucial protein participating to the physiopathology of a common metabolic myopathy namely the CPT2 deficiency, likely via its role in cellular redox balance and FA dynamics.

\section{Acknowledgements}

This work was supported by a grant from the Association Française contre les Myopathies (AFM, Trampoline Grant 2016-2017 \#19607) and by the INSERM.

\section{Author contributions}

FZB, CTR and VP performed experiments. JC and JLV generated Prnp-/- mice. JB analyzed data. FD prepared figures. SMR and FD conceived and designed the experiments; analyzed and interpreted the data and wrote the article.

\section{Conflict of interest}

The authors declare no competing interests. 


\section{References}

1. Smith EC, El-Gharbawy A, Koeberl DD (2011) Metabolic myopathies: clinical features and diagnostic approach. Rheumatic diseases clinics of North America 37 (2):201-217. doi:10.1016/j.rdc.2011.01.004

2. Bonnefont JP, Djouadi F, Prip-Buus C, Gobin S, Munnich A, Bastin J (2004) Carnitine palmitoyltransferases 1 and 2: biochemical, molecular and medical aspects. Mol Aspects Med 25 (56):495-520

3. Boufroura FZ, Le Bachelier C, Tomkiewicz-Raulet C, Schlemmer D, Benoist JF, Grondin P, Lamotte Y, Mirguet O, Mouillet-Richard S, Bastin J, Djouadi F (2018) A new AMPK activator, GSK773, corrects fatty acid oxidation and differentiation defect in CPT2-deficient myotubes. Human molecular genetics 27 (19):3417-3433. doi:10.1093/hmg/ddy254

4. Abmayr SM, Pavlath GK (2012) Myoblast fusion: lessons from flies and mice. Development 139 (4):641-656. doi:10.1242/dev.068353

5. Graham ZA, Gallagher PM, Cardozo CP (2015) Focal adhesion kinase and its role in skeletal muscle. Journal of muscle research and cell motility 36 (4-5):305-315. doi:10.1007/s10974-015-94153

6. Aguzzi A, Calella AM (2009) Prions: protein aggregation and infectious diseases. Physiological reviews 89 (4):1105-1152. doi:10.1152/physrev.00006.2009

7. Hirsch TZ, Martin-Lanneree S, Mouillet-Richard S (2017) Functions of the Prion Protein. Progress in molecular biology and translational science 150:1-34. doi:10.1016/bs.pmbts.2017.06.001

8. Loubet D, Dakowski C, Pietri M, Pradines E, Bernard S, Callebert J, Ardila-Osorio H, MouilletRichard S, Launay JM, Kellermann O, Schneider B (2012) Neuritogenesis: the prion protein controls beta1 integrin signaling activity. FASEB journal : official publication of the Federation of American Societies for Experimental Biology 26 (2):678-690. doi:10.1096/fj.11-185579

9. Schrock Y, Solis GP, Stuermer CA (2009) Regulation of focal adhesion formation and filopodia extension by the cellular prion protein (PrPC). FEBS letters 583 (2):389-393. doi:10.1016/j.febslet.2008.12.038

10. Huang S, Liang J, Zheng M, Li X, Wang M, Wang P, Vanegas D, Wu D, Chakraborty B, Hays AP, Chen K, Chen SG, Booth S, Cohen M, Gambetti P, Kong Q (2007) Inducible overexpression of wildtype prion protein in the muscles leads to a primary myopathy in transgenic mice. Proceedings of the 
National Academy of Sciences of the United States of America 104 (16):6800-6805. doi:10.1073/pnas.0608885104

11. Liang J, Parchaliuk D, Medina S, Sorensen G, Landry L, Huang S, Wang M, Kong Q, Booth SA (2009) Activation of p53-regulated pro-apoptotic signaling pathways in PrP-mediated myopathy. BMC genomics 10:201. doi:10.1186/1471-2164-10-201

12. Westaway D, DeArmond SJ, Cayetano-Canlas J, Groth D, Foster D, Yang SL, Torchia M, Carlson GA, Prusiner SB (1994) Degeneration of skeletal muscle, peripheral nerves, and the central nervous system in transgenic mice overexpressing wild-type prion proteins. Cell 76 (1):117-129. doi:10.1016/0092-8674(94)90177-5

13. Stella R, Massimino ML, Sandri M, Sorgato MC, Bertoli A (2010) Cellular prion protein promotes regeneration of adult muscle tissue. Molecular and cellular biology 30 (20):4864-4876. doi:10.1128/MCB.01040-09

14. Massimino ML, Ferrari J, Sorgato MC, Bertoli A (2006) Heterogeneous PrPC metabolism in skeletal muscle cells. FEBS letters 580 (3):878-884. doi:10.1016/j.febslet.2006.01.008

15. Smith JD, Moylan JS, Hardin BJ, Chambers MA, Estus S, Telling GC, Reid MB (2011) Prion protein expression and functional importance in skeletal muscle. Antioxidants \& redox signaling 15 (9):2465-2475. doi:10.1089/ars.2011.3945

16. Massimino ML, Peggion C, Loro F, Stella R, Megighian A, Scorzeto M, Blaauw B, Toniolo L, Sorgato MC, Reggiani C, Bertoli A (2016) Age-dependent neuromuscular impairment in prion protein knockout mice. Muscle \& nerve 53 (2):269-279. doi:10.1002/mus.24708

17. Nico PB, Lobao-Soares B, Landemberger MC, Marques W, Jr., Tasca Cl, de Mello CF, Walz R, Carlotti CG, Jr., Brentani RR, Sakamoto AC, Bianchin MM (2005) Impaired exercise capacity, but unaltered mitochondrial respiration in skeletal or cardiac muscle of mice lacking cellular prion protein. Neuroscience letters 388 (1):21-26. doi:10.1016/j.neulet.2005.06.033

18. Bonnefont JP, Bastin J, Behin A, Djouadi F (2009) Bezafibrate for treatment of an inborn mitochondrial ß-oxidation defect. The New England journal of medicine 360:838-840

19. Bonnefont JP, Bastin J, Laforet P, Aubey F, Mogenet A, Romano S, Ricquier D, Gobin-Limballe S, Vassault A, Behin A, Eymard B, Bresson JL, Djouadi F (2010) Long-term follow-up of bezafibrate treatment in patients with the myopathic form of carnitine palmitoyltransferase 2 deficiency. Clinical pharmacology and therapeutics 88 (1):101-108 
20. Naser R, Aldehaiman A, Diaz-Galicia E, Arold ST (2018) Endogenous Control Mechanisms of FAK and PYK2 and Their Relevance to Cancer Development. Cancers 10 (6). doi:10.3390/cancers10060196

21. Quach NL, Biressi S, Reichardt LF, Keller C, Rando TA (2009) Focal adhesion kinase signaling regulates the expression of caveolin 3 and beta 1 integrin, genes essential for normal myoblast fusion. Molecular biology of the cell 20 (14):3422-3435. doi:10.1091/mbc.E09-02-0175

22. Chiarugi P, Pani G, Giannoni E, Taddei L, Colavitti R, Raugei G, Symons M, Borrello S, Galeotti T, Ramponi G (2003) Reactive oxygen species as essential mediators of cell adhesion: the oxidative inhibition of a FAK tyrosine phosphatase is required for cell adhesion. The Journal of cell biology 161 (5):933-944. doi:10.1083/jcb.200211118

23. Olsen RK, Cornelius N, Gregersen N (2015) Redox signalling and mitochondrial stress responses; lessons from inborn errors of metabolism. Journal of inherited metabolic disease 38 (4):703-719. doi:10.1007/s10545-015-9861-5

24. Linsenmeier L, Altmeppen HC, Wetzel S, Mohammadi B, Saftig P, Glatzel M (2017) Diverse functions of the prion protein - Does proteolytic processing hold the key? Biochimica et biophysica acta Molecular cell research 1864 (11 Pt B):2128-2137. doi:10.1016/j.bbamcr.2017.06.022

25. McMahon HE, Mange A, Nishida N, Creminon C, Casanova D, Lehmann S (2001) Cleavage of the amino terminus of the prion protein by reactive oxygen species. The Journal of biological chemistry 276 (3):2286-2291. doi:10.1074/jbc.M007243200

26. Watt NT, Taylor DR, Gillott A, Thomas DA, Perera WS, Hooper NM (2005) Reactive oxygen species-mediated beta-cleavage of the prion protein in the cellular response to oxidative stress. The Journal of biological chemistry 280 (43):35914-35921. doi:10.1074/jbc.M507327200

27. Asthana A, Baksi S, Ashok A, Karmakar S, Mammadova N, Kokemuller R, Greenlee MH, Kong Q, Singh N (2017) Prion protein facilitates retinal iron uptake and is cleaved at the beta-site: Implications for retinal iron homeostasis in prion disorders. Scientific reports 7 (1):9600. doi:10.1038/s41598-017$08821-1$

28. Ashok A, Singh N (2018) Prion protein modulates glucose homeostasis by altering intracellular iron. Scientific reports 8 (1):6556. doi:10.1038/s41598-018-24786-1

29. Bravard A, Auvre F, Fantini D, Bernardino-Sgherri J, Sissoeff L, Daynac M, Xu Z, Etienne O, Dehen C, Comoy E, Boussin FD, Tell G, Deslys JP, Radicella JP (2015) The prion protein is critical for 
DNA repair and cell survival after genotoxic stress. Nucleic acids research 43 (2):904-916. doi:10.1093/nar/gku1342

30. Watt NT, Routledge MN, Wild CP, Hooper NM (2007) Cellular prion protein protects against reactive-oxygen-species-induced DNA damage. Free radical biology \& medicine 43 (6):959-967. doi:10.1016/j.freeradbiomed.2007.06.004

31. Schieber M, Chandel NS (2014) ROS function in redox signaling and oxidative stress. Current biology : CB 24 (10):R453-462. doi:10.1016/j.cub.2014.03.034

32. Chiodi P, Maccari F, Ramacci MT (1992) Tissue lipid accumulation by L-aminocarnitine, an inhibitor of carnitine-palmitoyltransferase-2. Studies in intact rats and isolated mitochondria. Biochimica et biophysica acta 1127 (1):81-86. doi:10.1016/0005-2760(92)90204-9

33. Djouadi F, Bonnefont JP, Munnich A, Bastin J (2003) Characterization of fatty acid oxidation in human muscle mitochondria and myoblasts. Molecular genetics and metabolism 78:112-118

34. Le Grand F, Rudnicki MA (2007) Skeletal muscle satellite cells and adult myogenesis. Current opinion in cell biology 19 (6):628-633. doi:10.1016/j.ceb.2007.09.012

35. Moulin M, Ferreiro A (2017) Muscle redox disturbances and oxidative stress as pathomechanisms and therapeutic targets in early-onset myopathies. Seminars in cell \& developmental biology 64:213223. doi:10.1016/j.semcdb.2016.08.003

36. Barbieri E, Sestili P (2012) Reactive oxygen species in skeletal muscle signaling. Journal of signal transduction 982794:1-17. doi:10.1155/2012/982794

37. Kozakowska M, Pietraszek-Gremplewicz K, Jozkowicz A, Dulak J (2015) The role of oxidative stress in skeletal muscle injury and regeneration: focus on antioxidant enzymes. Journal of muscle research and cell motility $36(6): 377-393$. doi:10.1007/s10974-015-9438-9

38. Paterson AW, Curtis JC, Macleod NK (2008) Complex I specific increase in superoxide formation and respiration rate by PrP-null mouse brain mitochondria. Journal of neurochemistry 105 (1):177-191. doi:10.1111/j.1471-4159.2007.05123.x

39. Collins SJ, Tumpach C, Groveman BR, Drew SC, Haigh CL (2018) Prion protein cleavage fragments regulate adult neural stem cell quiescence through redox modulation of mitochondrial fission and SOD2 expression. Cellular and molecular life sciences : CMLS 75 (17):3231-3249. doi:10.1007/s00018-018-2790-3 


\section{Figure legends}

Figure 1: CPT2-deficient myotubes exhibit FA alterations and increased SOD2 expression.

A. Representative images of myotubes from healthy subject (top panel) or CPT2-deficient patient (bottom panel) stained with MHC-I and PAX antibodies. Nuclei were stained with TO-PRO-3. Scale bar: $20 \mu \mathrm{M}$

B. Representative western blot and quantification of PAX protein from control or CPT2-deficient myotubes.

C. Representative images of myotubes from healthy subject (top panel) or CPT2-deficient patient (bottom panel) stained with MHC-I and FAK antibodies. Nuclei were stained with TO-PRO-3. Scale bar: $20 \mu \mathrm{M}$

D. Representative western blot and quantification of FAK protein from control or CPT2-deficient myotubes.

E. SOD2 mRNA expression in control and CPT2-deficient myotubes (left panel) and representative western blot and quantification of SOD2 protein from control or CPT2-deficient myotubes (right panel).

(A) and (C) Images are representative of three independent experiments carried out on 2 controls and 2 patients. In (B), (D) and (E) results are means of at least three independent experiments, each carried out on 3 controls and 4 patients. For (B), statistical significance was assessed by MannWhitney test, for (D) and (E), statistical significance was assessed by unpaired two-tailed Student's $t$ test. The $P$ values are indicated in the figure. Data are represented as mean \pm SEM.

Figure 2. CPT2-deficient myotubes display defects in $\operatorname{PrP}^{\mathrm{C}}$.

A. PRNP mRNA expression in control and CPT2-deficient myotubes.

B. Representative western blot and quantification of the various $\operatorname{PrP}^{\mathrm{C}}$ protein isoforms from control or CPT2-deficient myotubes.

C. Representative images of myotubes from healthy subject (top panel) or CPT2-deficient patient (bottom panel) stained with $\mathrm{PrP}^{\mathrm{C}}$ and PAX antibodies. Nuclei were stained with TO-PRO-3. Scale bar: $20 \mu \mathrm{M}$ 
D. Representative western blot and quantification of the various $\operatorname{PrP}^{C}$ protein isoforms in the cytoplasmic $(\mathrm{C})$ or nuclear $(\mathrm{N})$ fraction of control or CPT2-deficient myotubes.

In (A), (B) and (D) results are means of at least three independent experiments, each carried out on 3 controls and 4 patients. (C) Images are representative of two independent experiments carried out on 2 controls and 2 patients. For (A) and (B) statistical significance was assessed by unpaired two-tailed Student's $t$ test; for (D) statistical significance was assessed by Two-way ANOVA and the Tuckey test. The $P$ values are indicated in the figure. Data are represented as mean \pm SEM.

Figure 3. Inhibition of CPT2 enzymatic activity phenocopies CPT2 genetic deficit.

A. Representative western blot and quantification of MHC-I, SOD2, MYF5 and FAK proteins from vehicle or L-amino-Car-treated ( $2 \mathrm{mM}$ for 6 days) myotubes from healthy subject.

B. Representative western blot and quantification of the various $\operatorname{PrP}^{C}$ protein isoforms from vehicle or L-amino-Car-treated myotubes from healthy subject

Results are means of at least three independent experiments carried out on 3 controls. Statistical significance was assessed by paired two-tailed Student's $t$ test. The $\mathrm{P}$ values are indicated in the figure. Data are represented as mean \pm SEM.

\section{Figure 4. $\mathrm{PrP}^{\mathrm{C}}$ silencing recapitulates the phenotypes of CPT2-deficiency}

A. Representative western blot of $\operatorname{PrP}^{C}$ protein in myotubes from healthy subject treated with siRNA Non target (NT) or against PRNP (siPrPc).

B. Representative western blot and quantification of MHC-I, SOD2, MYF5 and FAK proteins in myotubes from healthy subject treated with siRNA Non target (NT) or against PRNP (siPrPc).

C. PRNP, MYH7, SOD2 and MYF5 mRNA expression in myotubes from healthy subject treated with siRNA Non target (NT) or against PRNP (siPrPc).

D. Representative images of myotubes from healthy subject treated with siRNA Non target (NT) (top panel) or against PRNP (siPrPc) (bottom panel) stained with PAX and MHC-I antibodies. nuclei were stained with TO-PRO-3. Scale bar: $20 \mu \mathrm{M}$

E. Calculation of the fusion index in myotubes from healthy subject treated with siRNA Non target (NT) or against PRNP (siPrPc).

F. Representative western blot of $\operatorname{PrP}^{C}$ protein in muscles from wild-type (WT) and $\operatorname{Prnp}^{-/-}$mice. 
G. Representative western blot and quantification of MHC-I, SOD2, and FAK proteins in muscles from WT controls and Prnp ${ }^{-/-}$mice.

H. Proposed schematic model explaining the relationship between CPT2 deficiency, ROS imbalance, $\operatorname{PrP}^{\mathrm{C}}$ cleavage, altered FA dynamics and impaired myotubes differentiation.

(A-C) Results are means of at least three independent experiments carried out on 3 controls. (D) Images are representative of two independent experiments on 2 controls. (E) Four fields of each condition were counted at $\times 20$ magnification. (F-G) Results are means of at least three independent experiments performed on 4 WT and $4 \operatorname{Prnp}^{-/-}$mice. Data are represented as mean \pm SEM. For (B), (C) and (E), statistical significance was assessed by paired two-tailed Student's $t$ test. For (G), statistical significance was assessed by unpaired two-tailed Student's $t$ test. The $\mathrm{P}$ values are indicated in the figure. Data are represented as mean \pm SEM.

\section{Appendix Fig S1: CPT2-deficient myotubes exhibit reduced CPT2 and MHC-I protein levels.}

A. Representative western blot and quantification of CPT2 protein from control or CPT2-deficient myotubes.

B. Representative western blot and quantification of MHC-I protein from control or CPT2deficient myotubes

Results are means of at least three independent experiments, each carried out on 3 controls and 4 patients. Statistical significance was assessed by unpaired two-tailed Student's $t$ test. The P values are indicated in the figure. Data are represented as mean \pm SEM.

\section{Appendix Fig S2: Schematic representation of $\operatorname{PrP}^{C}$ primary sequence and processing}

$\operatorname{PrP}^{C}$ is majorly found at the plasma membrane to which it is tethered through its glycosylphosphatidyl inositol (GPI) anchor. The alpha-cleavage yielding N1 and C1 fragments, occurs at position 111/112. The beta-cleavage yielding N2 and $\mathrm{C} 2$ fragments, occurs in the vicinity of octapeptides. $\mathrm{H} 1, \mathrm{H} 2, \mathrm{H} 3$ indicate alpha helices and $B 1$ and $\beta 2$ indicate beta sheets.

\section{Appendix Fig S3: CPT2-deficient myotubes exhibit thicker actin fibers}

Representative images of myotubes from healthy subject (top panel) or CPT2-deficient patient (bottom panel) stained TRITC phalloidin to visualize F-actin (ACT). Nuclei were stained with TO-PRO-3. Scale 
bar: $20 \mu \mathrm{M}$. Images are representative of three independent experiments carried out on 2 controls and 2 patients. 
A
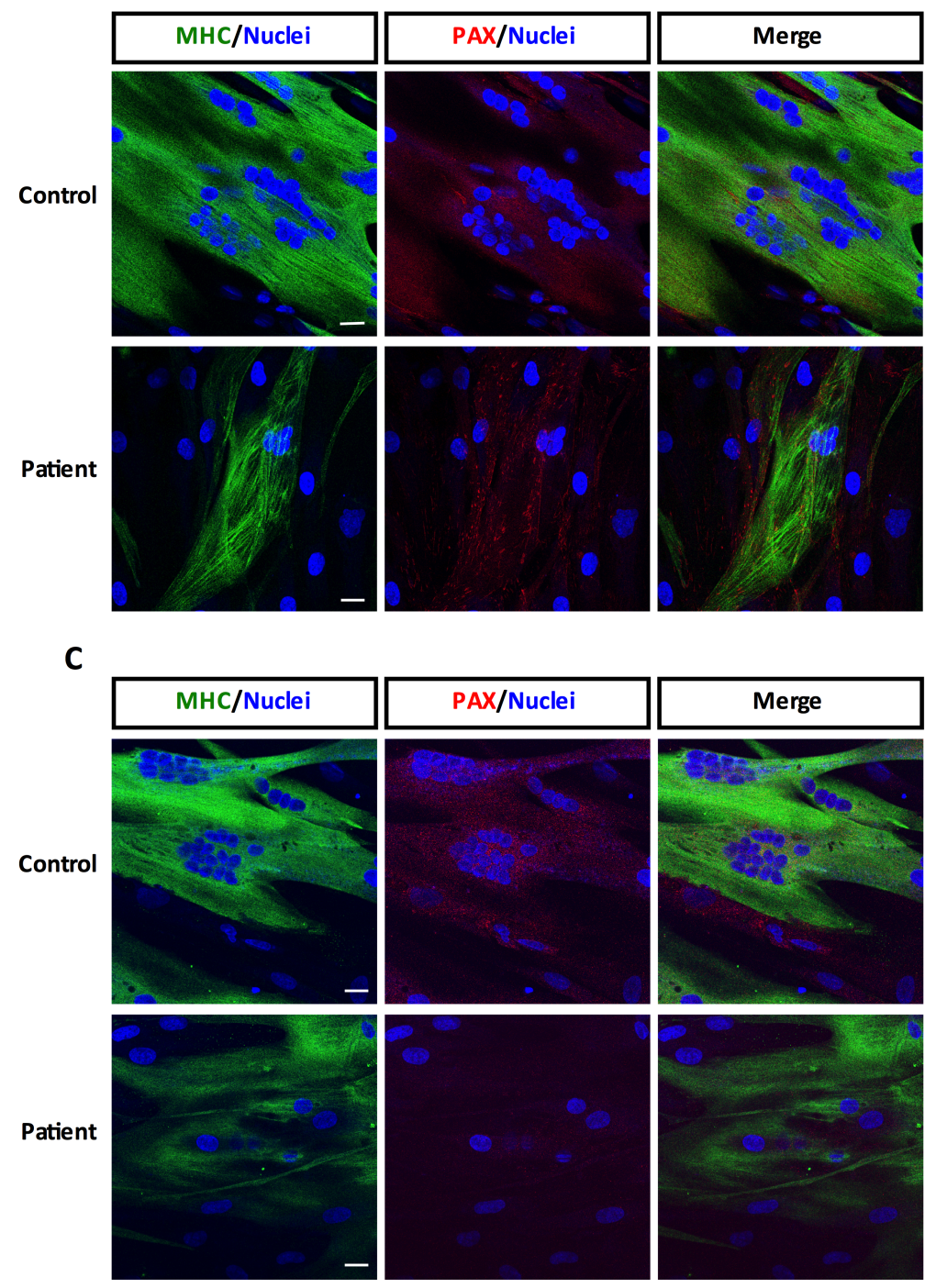

E

SOD2 mRNA

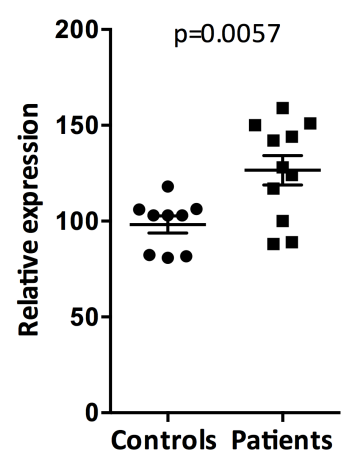

B

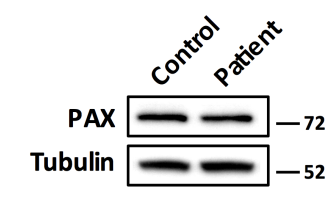

PAX protein

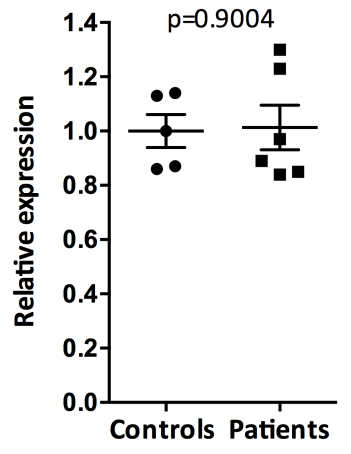

D

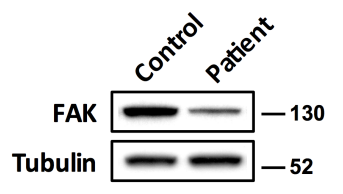

FAK protein

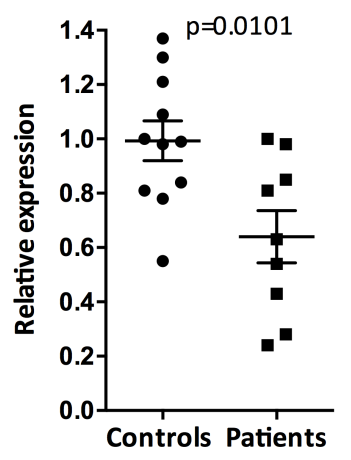

Figure 1 
A

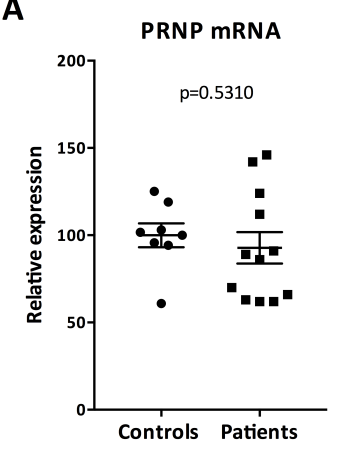

B

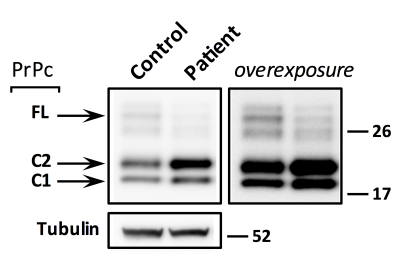

Tubulin $\longrightarrow 52$

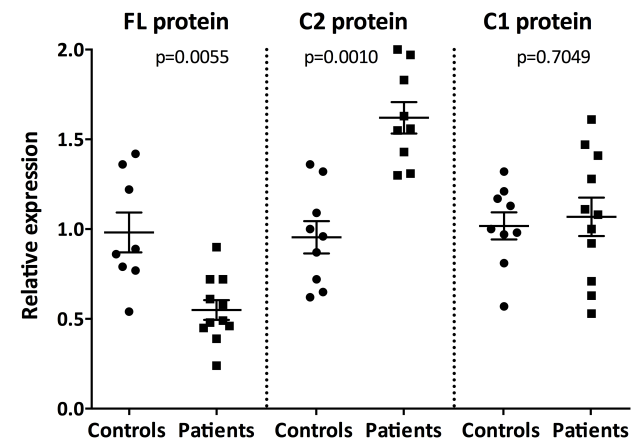

Controls Patients Controls Patients Controls Patients

C
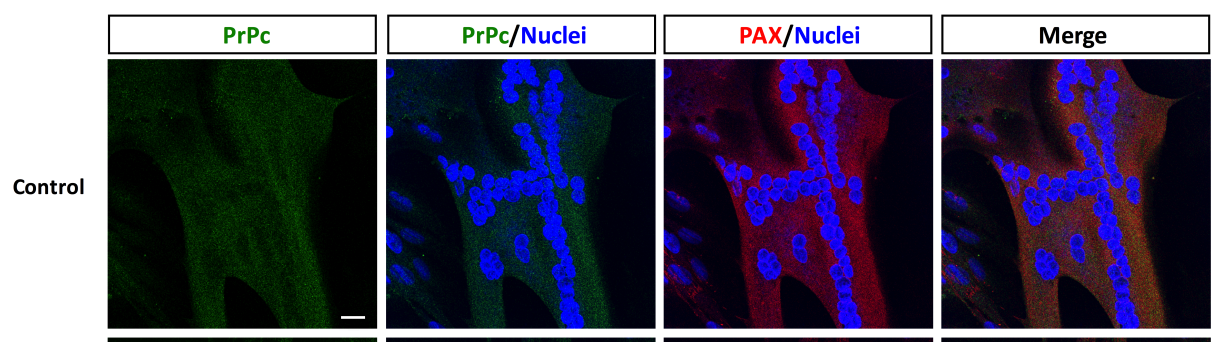

Patient
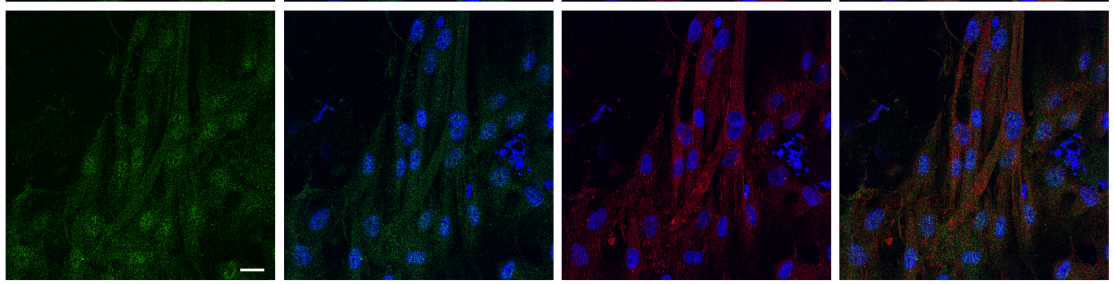

D
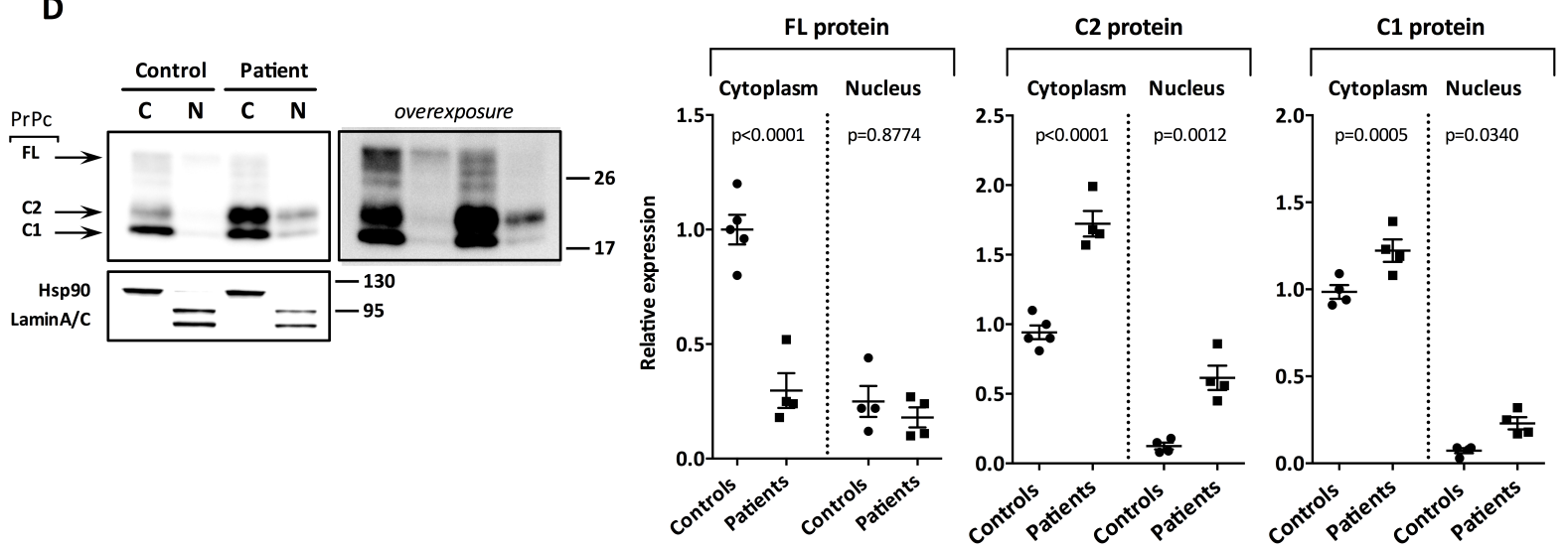

Figure 2 
A
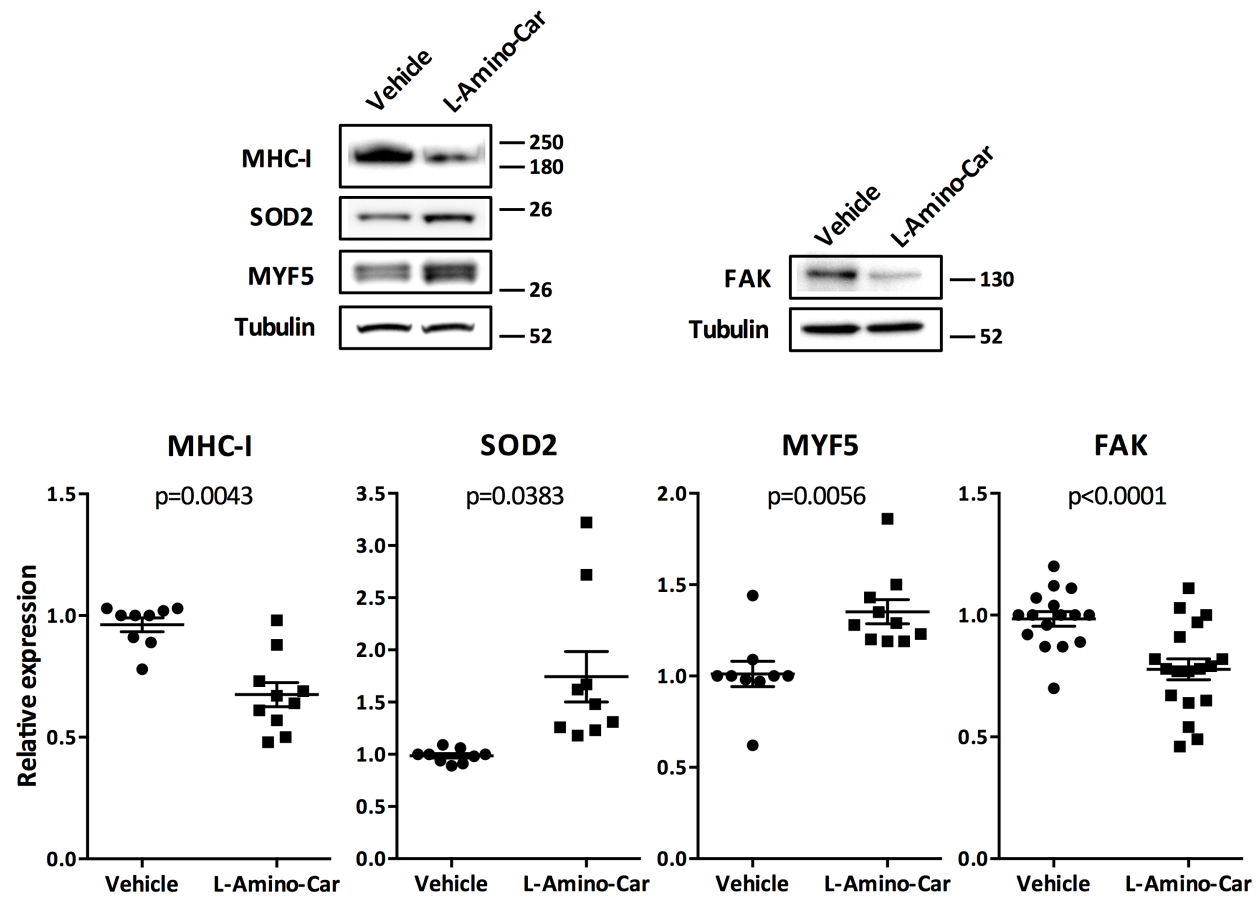

B

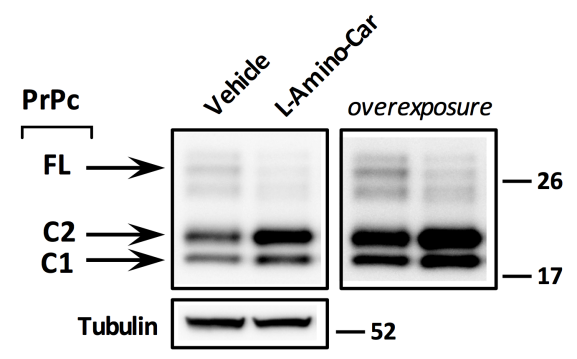

FL protein

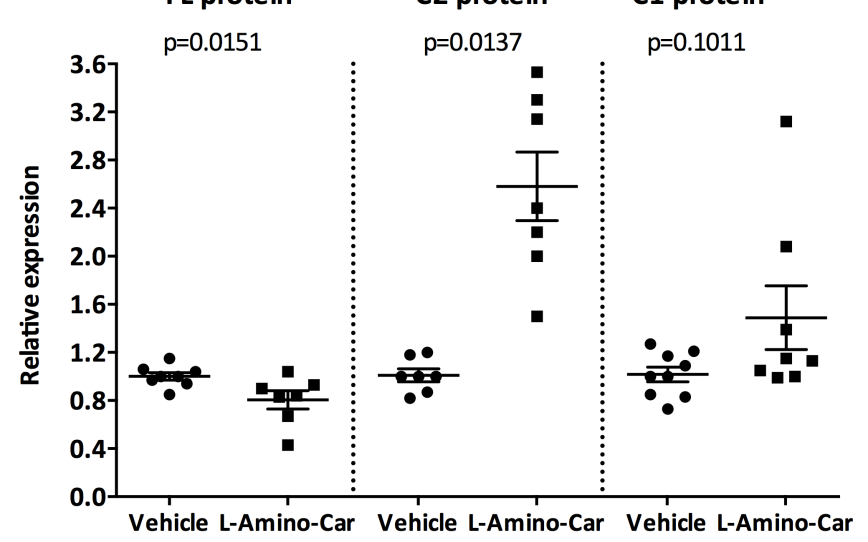

Figure 3 

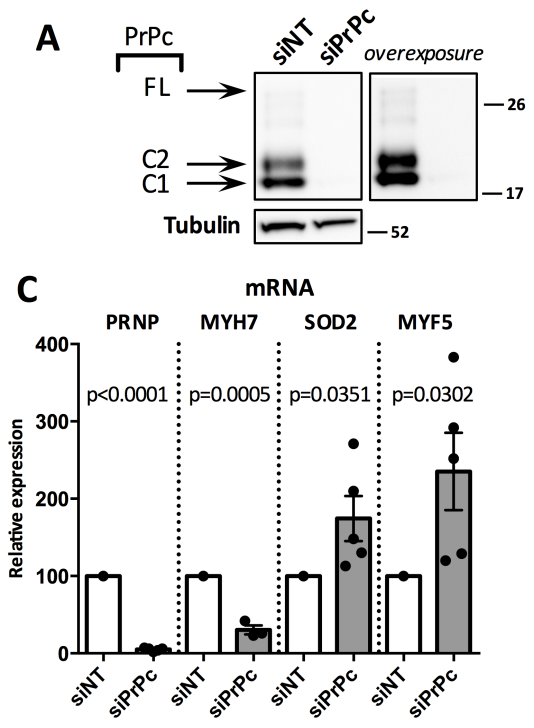

D

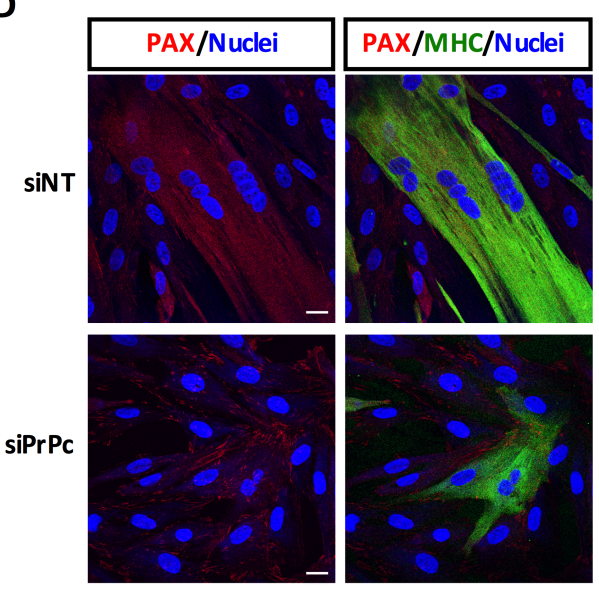

F

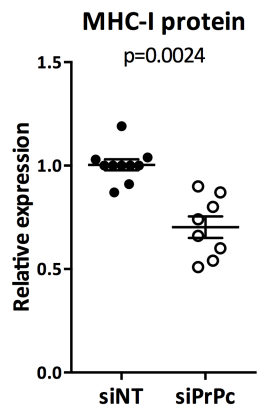

B

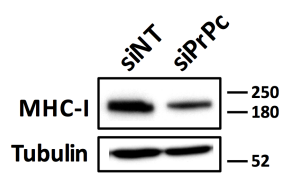

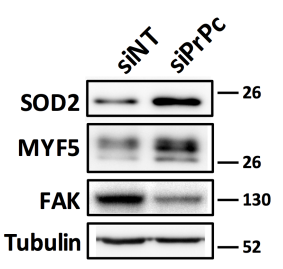

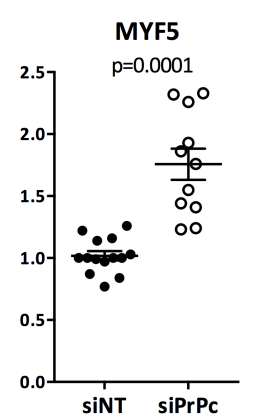

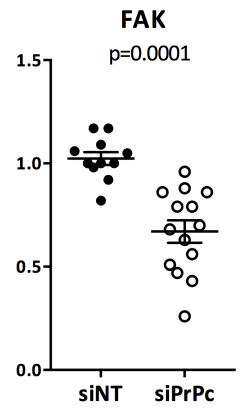

E
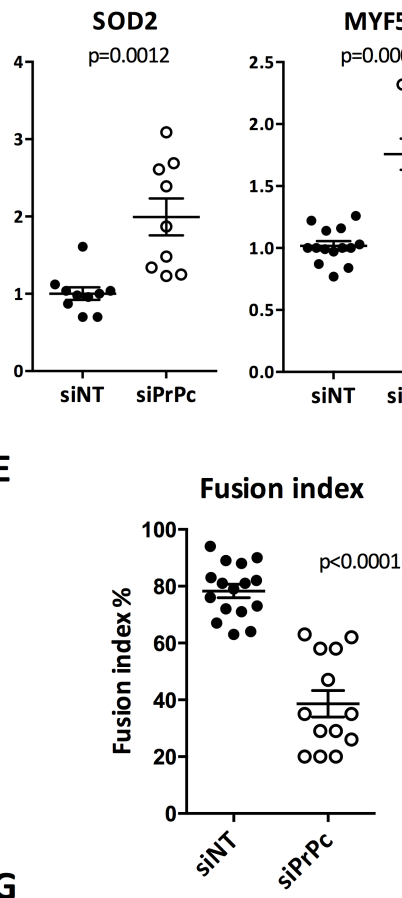

G

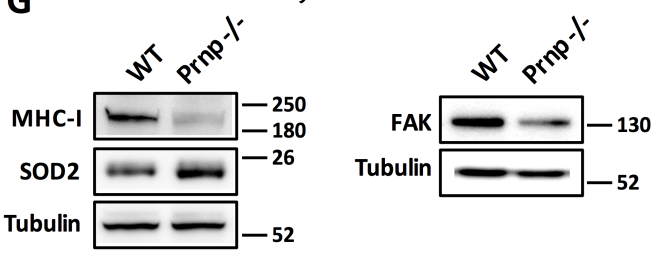

MHC-I

SOD2

FAK

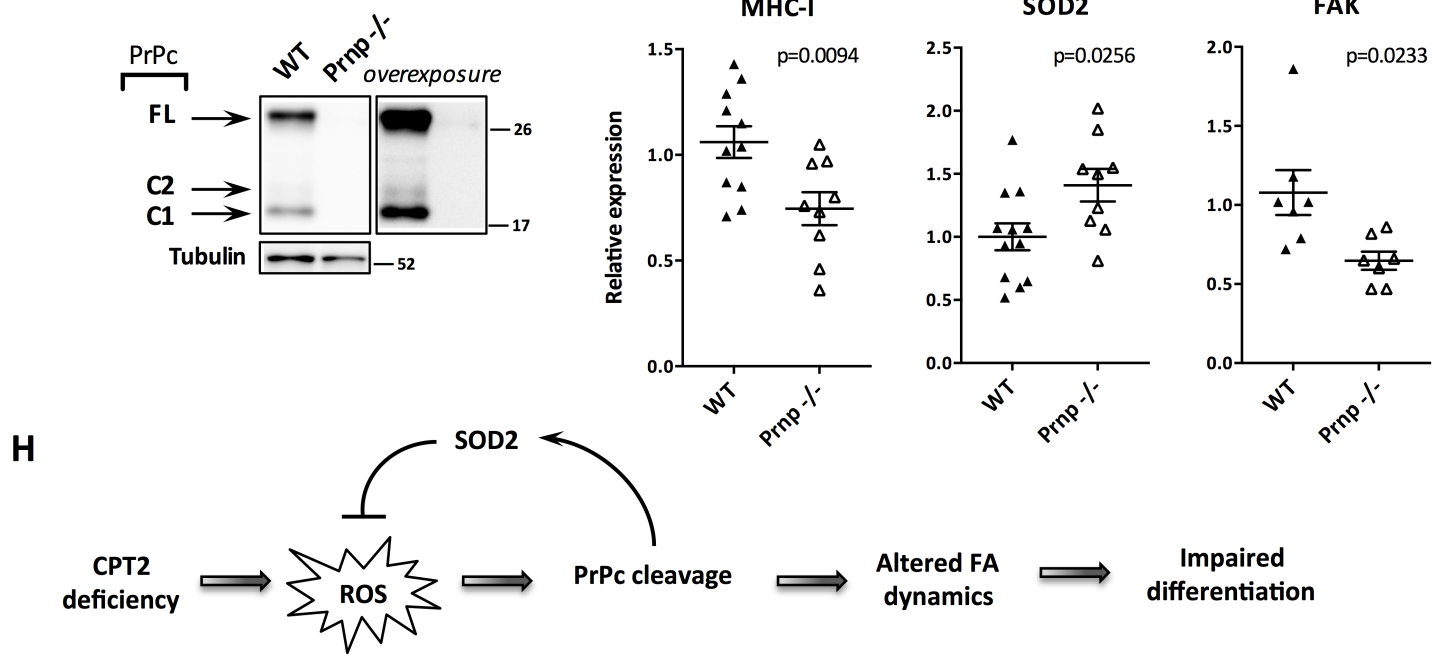

Figure 4 


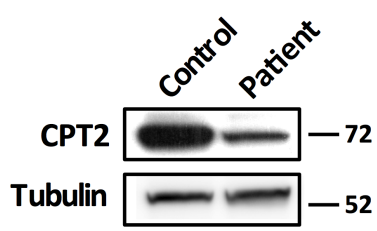

CPT2 protein

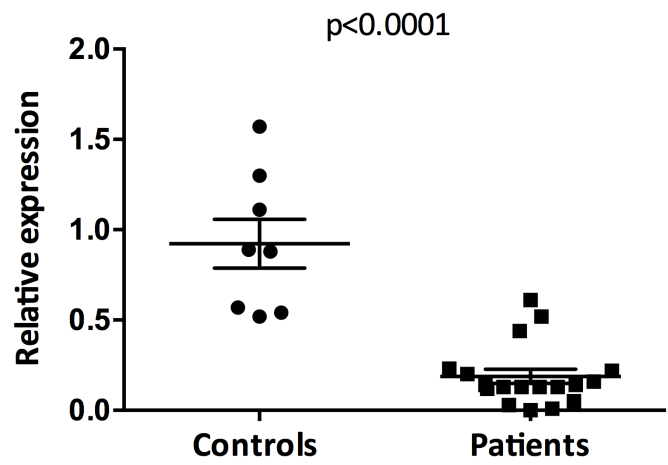

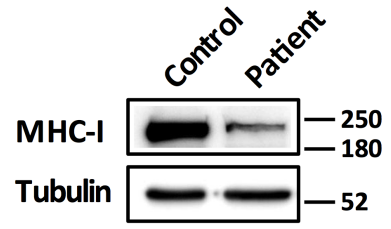

MHC-I protein

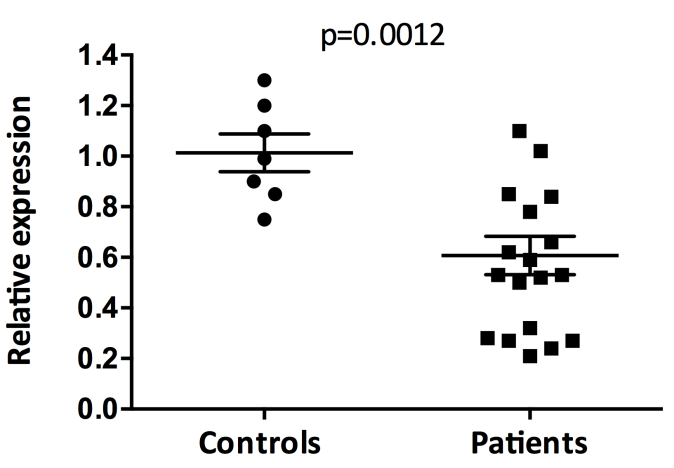

Figure S1 
Full length (FL)

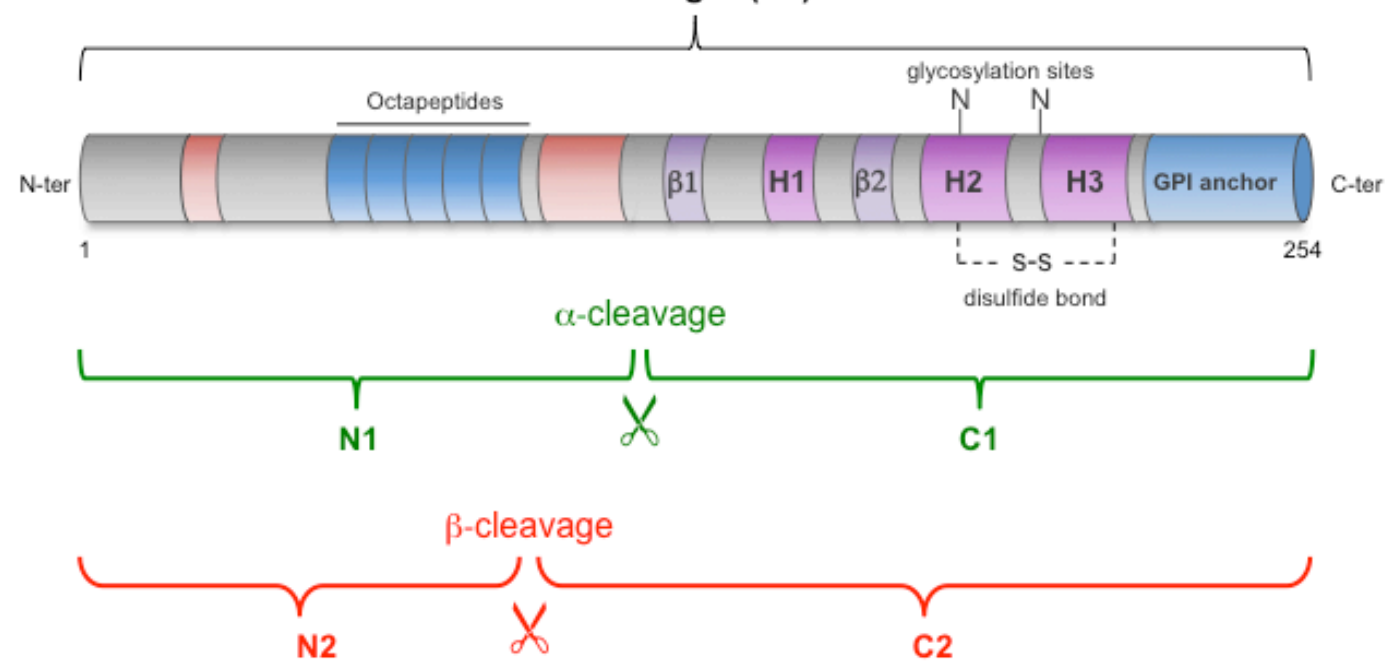

Figure S2 


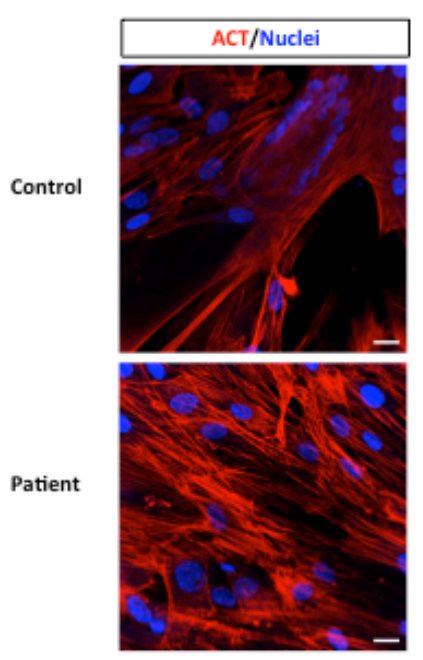

Figure S3 